\title{
The Overall Solution and Implement Strategy of Aircraft Digital Design Platform
}

\author{
Luo Mingqiang, Feng Haocheng \\ School of Aeronautic Science and Engineering \\ Beijing University of Aeronautics and Astronautics \\ Beijing, China \\ lmq19810222@163.com
}

\author{
Liu $\mathrm{Hu}, \mathrm{Wu}$ Zhe \\ School of Aeronautic Science and Engineering \\ Beijing University of Aeronautics and Astronautics \\ Beijing, China \\ liuhu@buaa.edu.cn
}

\begin{abstract}
The overall planning of aircraft digital design platform is proposed concerning the problems and difficulties in construction of the platform. The general mentality of constructing total solution of aircraft digital design platform is presented. The combing method of aircraft digital research and development process is proposed of separating the design results into phases and organizing the design activities hierarchically based on WBS (Work Breakdown Structure). The characteristics, demands and basic support elements of each target client groups are analyzed. The components and the architecture frame of aircraft digital design platform are defined. Finally, the implementation strategy based on the three dimensions of design phases, design departments and system levels is proposed.
\end{abstract}

Keywords- Aircraft engineering, Digital design, Platform, Architecture, System integration

\section{INTRODUCTION}

All manuscripts must be in English. These guidelines include complete descriptions of the fonts, spacing, and related information for producing your proceedings manuscripts. Please follow them and if you have any questions, direct them to the production editor in charge of your proceedings at Conference Publishing Services (CPS): Phone +1 (714) 821-8380 or Fax +1 (714) 761-1784.

Aviation enterprise digital construction has become one of the hot current researches [1-3]. After decades of development, all kinds of systems such as CAD, CAE, PDM, and PM have got different degrees of application in the enterprises, which promoted the ability of designing modern airplane greatly. However, because of the lack of overall planning in digital construction and the differences of procurement, all kinds of professional softwares and subsystems formed some information islands, and obstructed the advance of overall digital construction of plane design and the improve of design ability. What's more, it also caused a massive waste of resources. Problems show that, in order to standard and guide the digital construction process, overall planning and comprehensive digital design platform for airplanes is necessary.

This article will put forward overall solutions for digital design platform of airplanes, and offer the implementation strategies and steps for the platform, combining the status of our aviation enterprise and the problems encountered in aviation enterprise in digital construction.

\section{OVERALL SOLUTIONS FOR DIGITAL DESIGN PLATFORM}

\section{A. Overall thinking}

The solution of plane digital design platform will combine two thinking dimensions: standard complex product design based on $\mathrm{r} \& \mathrm{~d}$ (researching and development) process and the terminal application target - customer groupswhich should be considered when construct the design platform. Combined with the current situation of Chinese aircraft design institution of lead plane, terminal application target customer groups of the platform mainly include four categories: designers, officers, design managers and supporting designers. Fig. 1 is the overall thinking of the overall solutions for the formation of the aircraft digital design platform. Overall solutions for platform will begin from standardized design of the plane and put forward a digital $r \& d$ comb method based on WBS (Work Breakdown Structure), and then make models based on demands of all kinds of terminal application target customer groups and form the claims of the elements of platform for the target customer groups, and finally put forward components and system framework for the solution of the platform.

\section{B. Comb methods of digital $R \& D$ process based on WBS}

This paper presents comb methods of the section of design results and the hierarchy of design activity. The section of design results means that dividing the whole development process, which from the technical demonstration to the styling of design, into several stages to describe, and each stage ends with its landmark achievement for signs. The hierarchy of designing activity means that all activities of the planes' development will be delaminated managed in accordance with the granularity.

Ten levels activities mainly face to the first department in enterprise. Each activity can be divided into one or more than subprocess, and each node of the subprocess is the first activity, which mainly faces to the enterprise's secondary department. Activities of this class which can be directly distributed as the specific work are leaf nodes of explorations on model WBS, and they are also the most important basic unit and standard of building the digital design platform for planes. Combined with the current situation of the development of digital technology, the spread of the work each leaf nodes needs to consider input, output, resources, constraints, knowledge and so on 
The development work on whole departments may present by the form of professional department organization structure of enterprises as shown in Fig. 2.When every professional department tends to complete the task of the model in a certain stage, it will usually contain five constrained elements, namely input bag, output bag, list of the activities needed to complete, lists of support means to accomplish the activities, the given indicators and progress.

\section{Modeling based on target customer groups' demands}

We can guide the construction of overall solution for digital design platform by the demands of different target customer groups.

(1) Modeling based on demands of A class target customer groups (designers). A class of target customers group's demands of digital design platform focus on specific activities, including the following points: (1)the quick access to current activities process and the relationship with other activities; (2) clear format of output design and input design of the current activity; (3) clear digital means that current activity needs. Basic supportive elements aiming at A class of target customer groups include:(1)the management system of flow and its related elements;(2) a number of digital design, simulation tools and professional bag; (3) a number of fundamental database.

(2) Modeling based on class B target customer groups' demands. Class B target customer groups' demands will focus on management of scientific researching projects and the quality of research, including the following points: (1) complete the tasks basing on WBS; (2) related resources of every activity can be directly linked, such as outsourcing, materials, meetings, material, etc.; (3) reflect the execution real-timely. Basic supportive elements of class B class customer groups include: (1) the scientific management system; (2)the quality management system.

(3) Modeling based on class C target customer groups' demand. Class C target customer groups' demands are around the technology of model, including the following points:(1) control the state of aircrafts designing effectively; (2) carry out all the work orderly; (3)cast "the camp of the iron, the soldier of water", create standardized working process. Basic supporting elements of class $\mathrm{C}$ target customer groups include: (1) monitoring systems of model's index state; (2) management systems of standardized development process; (3)management systems of processing data.

(4) Modeling based on class D target customer groups' demands. Class D target customer groups' demands are around the application of the existing data in model designing work, including: (1)organize and manage a large amounts of data effectively;(2) blend existing data into the designer's r\&d activities to apply. Basic supportive elements of class D target customer groups include:(1) information management system aiming at mass data; (2) extraction method of data and data interface of external system.

\section{Framework and composition of the digital design platform for aircraft}

According to the analysis above, the plane digital design platform should consist of, controlling layer, applicationlayer and supporting layer, and elements and the platform framework of each layer are shown in Fig.3.

(1) presentation-layer. The basic function of platform portal is to provide relevant application of platform a unified entrance, which is convenient for the selection of all kinds of systems and communicating and prompting of related information.

(2) Controlling layer. It mainly includes process management system, data management system, project management system, quality management system and index management system.

(1) Process management system. It's overall integration working environment of aircrafts digital design platform, which is responsible for management and execution of process.

(2)Data management system. It is used in all the process and result data in management design.

(3) Project management system. It manages and tracks the whole process of the project from decision-making to the end.

(4) Quality management system. Similarly, it is used to monitor the quality each design activity completes based on design activity.

(5) Index management system. It mainly manages and monitors kinds of indexes of aircrafts comprehensively.

(3) Application-layer. It faces to specific designing task and focuses on the specific technical means of each activity. The application-layer includes application systems of each profession, in order to support all kinds of designing activities of researching tasks related to profession.

(4) Supporting layer. Supporting layer is mainly used to support the construction of professional application system which is related to application-layer, and it includes three parts: resources possessed by enterprise, R\&D supporting system and R\&D knowledge base.

\section{ENFORCEMENT STRATEGY OF DIGITAL DESIGN PLATFORM}

This paper presents an enforcement strategy to construct digital design platform of planes, which is based on three dimensionalities - design stage, professional department and system level. Design phase is divided into six stages, such as technical demonstration, plan design and so on; professional department is divided minimally into groups with $10 \sim 20$ human appropriately as the way in Fig.2; system levels divides as structure shown in Fig.3.

The construction of digital design platform of planes can be implemented by three phases. The first phase mainly researches typical objects selected from three dimensionalities, and the minimum unit is a system serving a certain profession and used for a certain design phase. The level of pilot system is usually supporting layer or application-layer system, and it causes no constraint to the designer's work form. The second phase can be promoted 
from the following aspects:1 promotion during design phase; (2) promotion among interior professional groups in professional department; (3) promotion among professional departments. Meanwhile, systems and organizations related to the control layer are also gradually improved, but they can only be commissioned in development department. The third phase consummates design platform based on construction achievements of the first and the second phase, and all system will be online and serve the whole model development.

\section{CONCLUSION}

This paper mainly introduces overall solutions and strategies of digital design platform for planes. The method is proposed combining with actual situation of aviation industry, refering to experience of the domestic and international advanced aircraft digital design platform. The aircraft digital design platform is still in its exploration stage, and there are a lot of problems need to be researched in some aspects, such as planning, design, implementation of promotion, recombination of process, integration of system.

\section{REFERENCES}

[1] Wu Guanghui,Liu Hu. Framework of Digital Design Support Systemof-systems for Large Airliners [J]. ACTA Aeronautica et Astronautica Sinica, 2008,29(5):1386-1394 (in Chinese).

[2] Fan Yushun. Prototype system research on open conceptual aircraft design[J]. Computer Integrated Manufacturing Systems, 2002, 8(12):925-930 (in Chinese).

[3] Feng Lei, Fan Yuqing. Engineering Data Management Technology in Aircraft Digital Design[J]. Computer Integrated Manufacturing Systems,, 2004, 10(2):183-187 (in Chinese).

[4] Fan Wenhui, Ge Zhengyu, He Shan, Xiong Guangleng. Windchill-Based Product Data Management System[J]. Computer Integrated Manufacturing Systems, 2002, 8(9):715-719 (in Chinese).

[5] Malone, B., Papay, M. ModelCenter: An Integration Environment for Simulation Based Design[R]. Simulation Interoperability Workshop, Orlando, FL, Mar., 1999

[6] Li Tingting, Gu Liangxian. Multidisciplinary Design Optimization of Missile Based on FIPER Software[J]. Computer Simulation, 2009, 26(11):61-64 (in Chinese).

[7] ANSYS, Inc. ANSYS Workbench. http:// www.ansys.com/ products/workbenchportal.asp

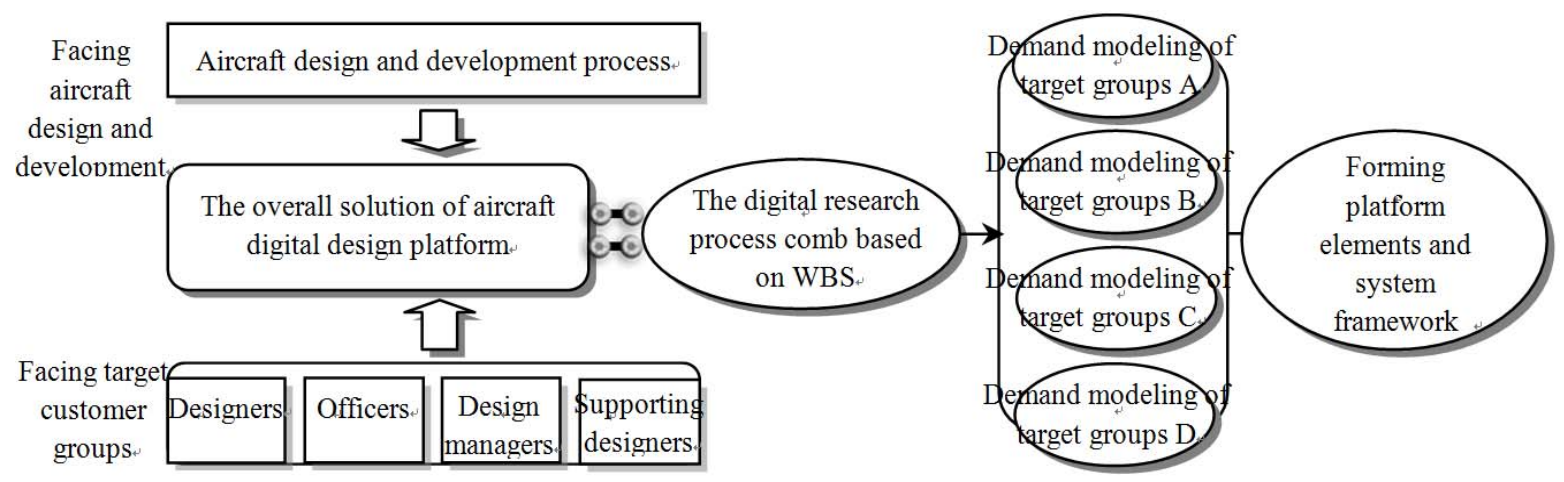

Figure 1. The overall thinking of solutions for aircraft digital design platform

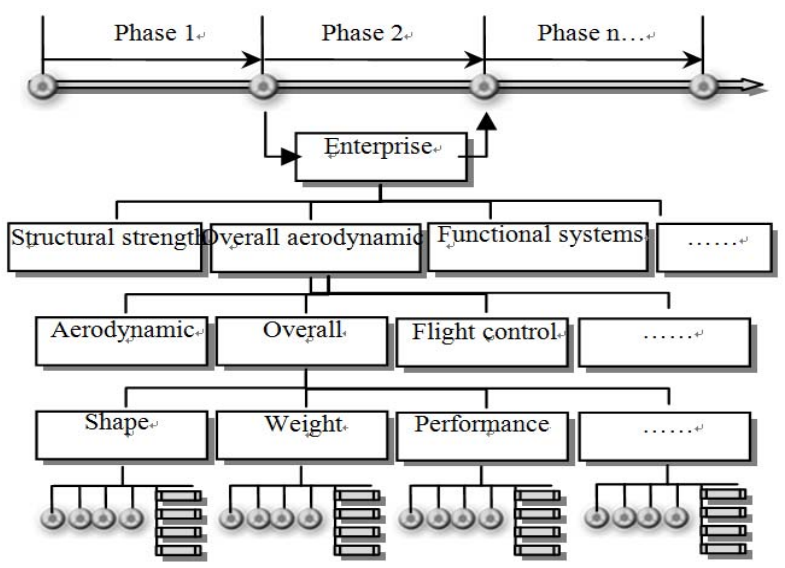

() Design activities design activities

Figure 2. R \& D activities organized by specialized departments 


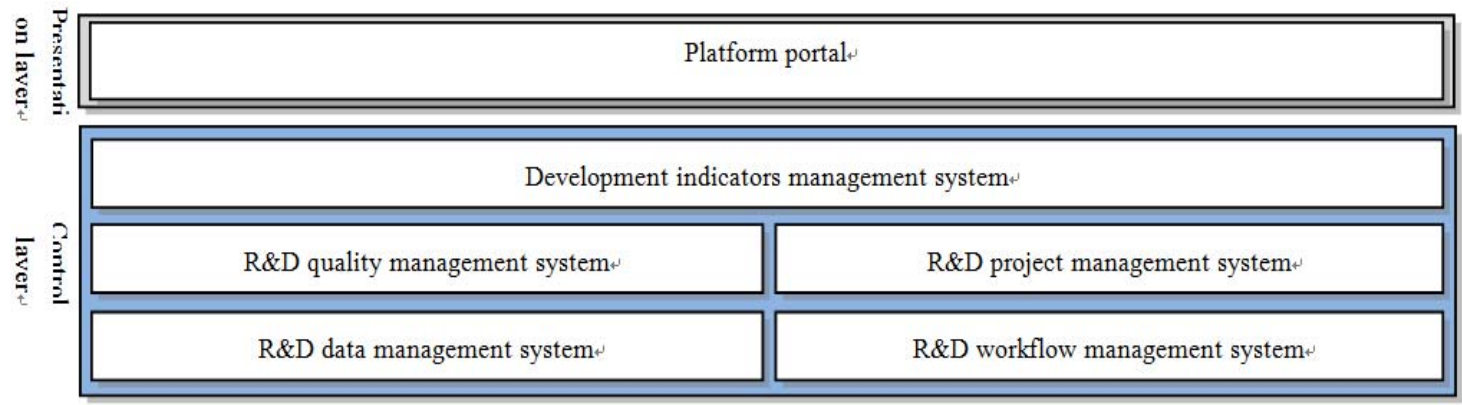

\begin{tabular}{|c|c|c|c|c|c|c|c|c|}
\hline 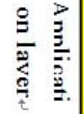 & $\begin{array}{l}\text { Overall } \\
\text { design } \\
\text { svstem }\end{array}$ & $\begin{array}{l}\text { Structure } \\
\text { design } \\
\text { svstem }\end{array}$ & $\begin{array}{l}\text { Strength } \\
\text { design } \\
\text { svstem }\end{array}$ & $\begin{array}{l}\text { Flight } \\
\text { control } \\
\text { desion }\end{array}$ & $\begin{array}{l}\text { Hydrauli } \\
\mathrm{c} \text { design } \\
\text { svstem }\end{array}$ & $\begin{array}{l}\text { Avionics } \\
\text { design } \\
\text { svstem }\end{array}$ & $\begin{array}{l}\text { Fuel } \\
\text { design } \\
\text { svstem }\end{array}$ & ....... \\
\hline
\end{tabular}

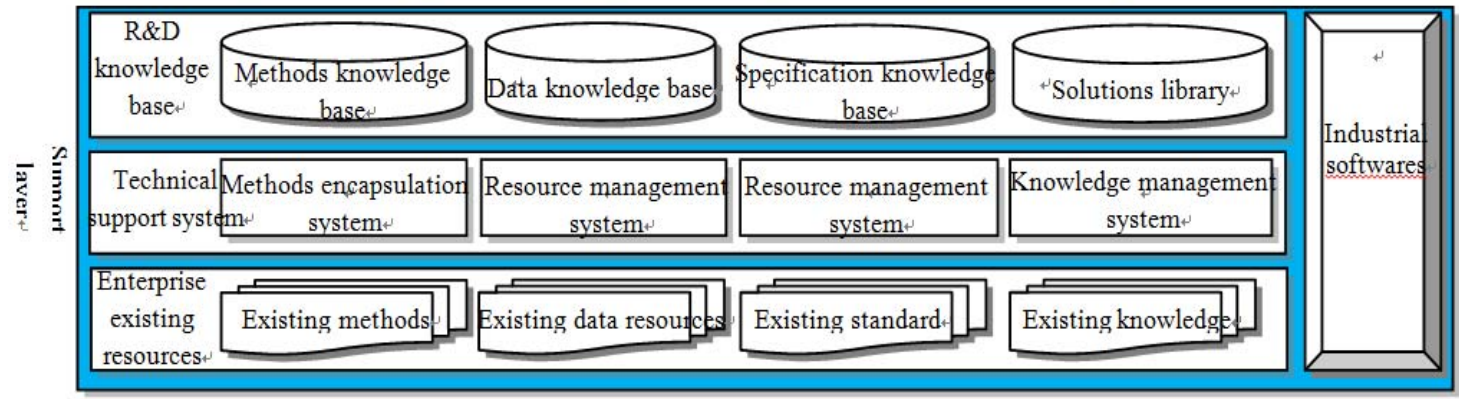

Figure 3. Aircraft digital design platform composition and framework 